\title{
Genetic analysis of yield and heat stress related traits in wheat (Triticum aes- tivum L. em. Thell) using microsatellite markers
}

\author{
Mamta Gupta, Veena Chawla, Pankaj Garg*, Neelam Yadav, Renu Munjal and Bunty \\ Sharma
}

Department of Genetics and Plant Breeding, ${ }^{1}$ Department of Molecular Biology and Biotechnology CCS Haryana Agricultural University, Hisar-125 004 (Haryana), INDIA

*Corresponding author. E-mail: czarpankaj@gmail.com

Received: January 23, 2015; Revised received: July 28, 2015; Accepted: September 20, 2015

\begin{abstract}
Microsatellite markers were used for genetic analysis of terminal heat tolerance in $\mathrm{F}_{2}(\mathrm{PBW} 373 \times \mathrm{WH} 1081)$ population of wheat (Triticum aestivum L. em. Thell). Two parents were evaluated in field under normal sown and late sown conditions. For genotyping DNA from both parents PBW373 and WH1081 was amplified using 200 SSRs. Only 22 SSRs produced polymorphic bands, of size between 100 to $300 \mathrm{bp}$ and an average of 1.45 alleles. The single marker analysis identified 19 markers indicating the putative QTLs for yield, its components and heat stress related physiological traits. The number of markers on these 16 linkage groups varied from one to four. On A genome 13 QTLs on B genome 5 QTLs and on D genome 9 QTLs were identified, respectively. The A, B and D genomes had $1360.3 \mathrm{cM}, 272.4 \mathrm{cM}$ and $919.5 \mathrm{cM}$ of linkage coverage with average interval distances of $104.63 \mathrm{cM}, 54.48 \mathrm{cM}$ and $102.16 \mathrm{cM} /$ Marker. A total of nine QTLs were resolved following composite interval mapping, one QTL was detected at a LOD score equal to threshold value of 2.5 while eight at LOD scores above the threshold value. All the nine QTLs were shown to be on definitive location on chromosome 3A (QDh.CCSHAU-3A, QDa.CCSHAU-3A and QPm.CCSHAU-3A), chromosome (QBm.CCSHAU-5A, QCtd.CCSHAU-5A and QCl.fl.CCSHAU-5A), chromosome6A (QPh.CCSHAU-6A) and chromosome3B (QTgw.CCSHAU and QMts.CCSHAU-3B). Use of these markers save times, resources and energy that are needed not only for raising large segregating populations for sveral generations, but also for estimating the parameters used for selection.
\end{abstract}

Keywords: Genotyping, QTL, MAS, Wheat

\section{INTRODUCTION}

Wheat is among the major three cereal crops, with over 600 million tones being produced annually. It is traditionally grown as a cool-season crop, but with the increased availability of more widely adapted germplasm, its production has expanded into warmer regions (Badaruddin et al., 1999). Continuous hightemperature stress for wheat has been defined as when the mean average temperature of the coolest month is greater than $17.5^{\circ} \mathrm{C}$ (Fischer and Byerlee, 1991), but there are many areas world wide where the coolest month temperature is higher. These areas are exposed to terminal heat stress, since there is rise in temperatures in grain filling period (Rane et al., 2007). Based on the special report, it is predicted that the annual daily maximum temperature is likely to increase by about $1-3^{0} \mathrm{C}$ by mid-twenty-first century and by about $2-5^{0} \mathrm{C}$ by the late twenty first century (IPCC, 2012). So, it is expected that future wheat will be exposed to higher heat stress. Wheat experiences heat stress to varying degrees at different phenological stages but heat stress during the reproductive phase is more harmful than during the vegetative phase as high temperature disturbs mobilization of resources to grain development leading to direct effect on grain number and grain weight (Wollenweber et al., 2003). Wheat production under late sown conditions in India is substantially low, due to heat stress during grain filling (Tewolde et al., 2006). High temperatures shorten the grain filling period significantly in bread and durum wheat genotypes, because of significant interaction of each genotype with temperature (Dias and Lidon, 2009). With the development of methodologies for the analysis of plant gene structure and function, molecular markers have been utilized for identification of traits, to locate the gene(s) for a trait of interest on a plant chromosome and for the construction of genetic linkage maps. Direct selection under field conditions is generally difficult because uncontrollable environmental factors adversely affect the precision and repeatability of such traits. Assessment of heat tolerance at the molecular level is more meaningful than at phenotypic level as the later involves data on morphological traits which are environmental dependent. Available genetic diversity in wheat offers opportunity for the breeders to develop genotypes with wider adaptability having resistance to biotic and abiotic stresses by selection of recombinants of desired genes. The simple sequence repeats (SSR) markers can help breeders to 
select genotypes carrying gene(s) of interest (Sadat et al., 2013), therefore, molecular maps based on these markers provide the breeders efficient strategies that may optimize time and resources and facilitate their manipulation in segregating plant breeding populations. These are powerful tools for many studies for genome characterization, detection of quantitative trait loci (QTL) for both abiotic and biotic stresses, evolutionary studies, and for marker assisted selection (MAS) (Peleg et al., 2008; Chu et al., 2010 and Sadat et al., 2013). In bread wheat, a variety of complex traits have been subjected to QTL analysis (Borner et al., 2002; Wang et al., 2009, 2010; Wu et al., 2010; Rustgi et al., 2013) using SSR markers. Therefore, in present investigation genetic analysis of terminal heat tolerance was conducted to identify QTLs for stress related traits of wheat.

\section{MATERIALS AND METHODS}

Morphological characterization: A population of $152 \mathrm{~F}_{2}$ plants from a cross of PBW373 $\times$ WH1081 was evaluated along with their parental genotypes and five check varieties (Raj3765, DBW17, WH730, WH711and PBW343) for phenological traits; days to heading, days to anthesis, days to physiological maturity, grain filling duration, plant height, number of productive tillers/plant, number of grains/spike, 1000 grain weight, grain yield/plant, biomass/plant, harvest index and physiological traits- canopy temperature depression, membrane thermostability and chlorophyll fluorescence. Parents and check varieties were sown in 3 meter paired rows in three replication in normal conditions, $\left(E_{1}\right)$ on $29^{\text {th }}$ November, 2011 and heat stress conditions, $\left(\mathrm{E}_{2}\right)$ on $3^{\text {rd }}$ January, 2012 in randomized block design at wheat research area, Department of Genetics and Plant Breeding, CCS HAU, Hisar. $F_{2}$ population was grown in 10 rows each with two meter row length under heat stress environment $\left(E_{2}\right)$. Row to row and plant to plant distance was kept at $25 \mathrm{~cm}$ and $10 \mathrm{~cm}$, respectively, so as to raise the plants under space planting conditions. $60 \mathrm{~kg} \mathrm{~N}: 40 \mathrm{~kg} \mathrm{P}_{2} \mathrm{O}_{5}$ and 40 $\mathrm{kg} \mathrm{K}_{2} \mathrm{O}$ per ha were applied at the time of sowing while $60 \mathrm{~kg} \mathrm{~N}$ per ha was top-dressed 21 days after sowing coinciding with crown root initiation. The observations were recorded on five randomly selected plants from each replication of parental genotypes and checks in both the environments, $\mathrm{E}_{1}$ and $\mathrm{E}_{2}$ (normal and heat stress conditions), single plant data was recorded on $152 \mathrm{~F}_{2}$ plants of each of the cross PBW373 $\times$ WH1081 under stress conditions only.

Molecular characterization using SSR markers: Genomic DNA was isolated from each of parental genotypes, check varieties and $\mathrm{F}_{2}$ plants using CTAB method of Saghai-Maroof et al. (1984). Agarose gel $(0.8 \%)$ electrophoresis was used to check quality and quantity of genomic DNA by running DNA samples along with standard marker.

A total of 200 simple sequence repeats (SSR) markers widely distributed on different wheat chromosomes were used in this study. PCR amplification of genomic DNA from parents, check varieties and $F_{2}$ population was carried out in PCR machine 'Bench top lab systems-BT-B960' using following conditions: Initial Denaturation- $95^{\circ} \mathrm{C}$ for $5 \mathrm{~min}$, denaturation $-94^{\circ} \mathrm{C}$ for 1 min, Annealing $-50^{\circ} \mathrm{C}$ to $65^{\circ} \mathrm{C}$ for $1 \mathrm{~min}$, Extension- $72^{\circ}$ $\mathrm{C}$ for $1 \mathrm{~min}, 35$ cycles and Final Extension- $72^{\circ} \mathrm{C}$ for $10 \mathrm{~min}$. PCR amplified DNA products were resolved by submerged horizontal electrophoresis in $2.5 \%(\mathrm{w} / \mathrm{v})$ agarose gel. For better resolution amplification products were also resolved on $6 \%$ polyacrylamide gels using Amersham Biosciences system as described by Chen et al. (1997).

SSR amplification profiles were scored visually, with $\mathrm{A}$ and $\mathrm{B}$ codes for presence of specific band in tolerant and sensitive parent, respectively as: A- homozygous tolerant, B- homozygous sensitive, $\mathrm{AB}$ - heterozygous and '-' missing for each wheat genotype. Single marker analysis was carried out by fitting the data on the SSRs (as independent variable) and the phenotypic data (as dependent variable) of 152 plants $F_{2}$ population using single linear regression model given as $\mathrm{y}=$ bo $+\mathrm{b} 1 \mathrm{x}+\mathrm{e}$ (Basten et al., 2000). The estimated genetic map of SSRs was used as a framework for the positioning of QTL using composite interval mapping (Zeng, 1994; Basten et al., 2000) by associating the values for different traits. The percentage of variation and additive effect of each of phenotypic traits caused by the presence of QTLs were also estimated using WinQTL Cartographer version-2.5.

\section{RESULTS AND DISCUSSION}

Analysis of variance for five check varieties and two parents conducted in two environments, $E_{1}$ and $E_{2}$ indicated significant variation due to genotypes for every trait studied except for chlorophyll fluorescence. Kumar et al. (2014) evaluated the 50 diverse wheat genotypes and exhibited highly significant differences at genotypic level for all the traits studied, under normal and heat-stress environments. All the traits expressed significant interaction with environments, indicating that all traits respond to high temperature in different ways in different genotypes. Talukdar et al. (2014) reported one of the first linkage maps in wheat using genotype by sequencing SNP markers to extreme response to post anthesis heat stress conditions and also evaluated that the molecular markers Xbarc113 and AFLP AGCTCG-347 on chromosome 6A, Xbarc121 and Xbarc49 on 7A, gwm 18 and Bin1130 on 1B, Bin178 and Bin81 on 2B and Bin747 and Bin1546 on $1 \mathrm{D}$ were associated with these QTL. Analysis of variance, exhibited highly significant differences at genotypic level for all the traits studied, under normal and heat-stress environments. All the traits expressed significant interaction with environments, indicating that all traits respond to high temperature in different ways in different genotypes. This variability gives suf- 
Table 1. DNA amplification profile of parental varieties of two wheat crosses using SSRs.

\begin{tabular}{lc}
\hline & PBW373 $\times$ WH1081 \\
\hline Number of markers used & 200 \\
Number of markers that did not show amplification & 42 \\
Number of markers that show amplification & $158(79 \%)$ \\
Number / percentage of amplified markers showing polymorphisum & 22 \\
Number of alleles detected using polymorphic markers & 32 \\
Range of alleles & $1-3$ \\
Average number of alleles & 1.45 \\
Size of products & $100-300 \mathrm{bp}$ \\
\hline
\end{tabular}

Table 2. Association of heat stress and related traits and primers detected by single marker analysis using $\mathrm{F}_{2}$ population of cross PBW373 $\times$ WH1081.

\begin{tabular}{|c|c|c|c|}
\hline Traits & Name of markers & Chromosome & Significance \\
\hline Days to heading & Xbarc1044, Xgwm666.2, Xgwm635 & $3 \mathrm{~A}, 3 \mathrm{~A}, 7 \mathrm{~A}$ & $*, *, *$ \\
\hline Days to anthesis & Xgwm635, Xgdm125 & $7 \mathrm{~A}, 4 \mathrm{D}$ & $*, *$ \\
\hline Days to physiological maturity & $X w m c 473$ & $4 \mathrm{D}$ & $*$ \\
\hline Grain filling duration & Xbarc142, Xwmc473 & $5 \mathrm{~A}, 4 \mathrm{D}$ & $*, *$ \\
\hline Plant height $(\mathrm{cm})$ & Xbarc142, Xgwm337, Xwmc336 & $5 \mathrm{~A}, 1 \mathrm{D}, 1 \mathrm{D}$ & $*, *, *$ \\
\hline Number of productive tillers/ plant & Xgwm2, Xgwm666.2 & $3 \mathrm{~A}, 3 \mathrm{~A}$ & $*, *$ \\
\hline Number of grains/spike & Xbarc142 & $5 \mathrm{~A}$ & $*$ \\
\hline 1000 grain weight $(\mathrm{g})$ & Xbarc142, Xwmc473 & $5 \mathrm{~A}, 4 \mathrm{D}$ & $*, *, *$ \\
\hline Grain yield/plant $(\mathrm{g})$ & Xgwm2 & $3 \mathrm{~A}$ & $*$ \\
\hline Membrane thermostability (\%) & Xgwm156 & $3 \mathrm{~B}$ & $*$ \\
\hline Chlorophyll fluorescence $\left(\mathrm{F}_{\mathrm{V}} / \mathrm{F}_{\mathrm{M}}\right)$ & Xgwm611 & $7 \mathrm{~B}$ & $*$ \\
\hline
\end{tabular}

Table 3. Distribution of markers over 16 chromosomes categorized as framework markers and their genetic lengths.

\begin{tabular}{llll}
\hline Linkage group & \multicolumn{1}{c}{ SSRs } & Length (cM) \\
\hline & Number of markers & \multicolumn{1}{c}{ Name of markers } & $24.3 \mathrm{cM}$ \\
1A & 1 & $X w m c 336$ & $131.3 \mathrm{cM}$ \\
2A & 1 & $X w m c 170$ & $326.4 \mathrm{cM}$ \\
3A & 4 & $X g w m 2, X g w m 369, X b a r c 1044, X g w m 666.2$ & $181.0 \mathrm{cM}$ \\
4A & 1 & $X w m c 313$ & $207.5 \mathrm{cM}$ \\
5A & 2 & $X g w m 293, X b a r c 142$ & $190.9 \mathrm{cM}$ \\
6A & 2 & $X w m c 398, X b a r c 142$ & $296.0 \mathrm{cM}$ \\
7A & 2 & $X g w m 635, X g w m 260$ & $25.0 \mathrm{cM}$ \\
1B & 1 & $X g w m 413$ & $102.8 \mathrm{cM}$ \\
3B & 2 & $X g w m 156, X b a r c 147$ & $55.6 \mathrm{cM}$ \\
6B & 1 & $X w m c 398$ & $89.0 \mathrm{cM}$ \\
7B & 1 & $X g w m 611$ & $47.2 \mathrm{cM}$ \\
1D & 2 & $X g w m 337, X w m c 336$ & $274.1 \mathrm{cM}$ \\
2D & 2 & $X b a r c 142, X w m c 170$ & $131.5 \mathrm{cM}$ \\
3D & 2 & $X g d m 8, X c f d 70$ & $386.2 \mathrm{Cm}$ \\
4D & 2 & $X w m c 473, X g d m 125$ & $80.5 \mathrm{cM}$ \\
7D & 1 & $X g w m 635$ & $1360.3 \mathrm{Cm}$ \\
A genome & 13 & & $54.48 \mathrm{Cm}$ \\
B genome & 5 & & $919.5 \mathrm{Cm}$ \\
D genome & 9 & & \\
\hline
\end{tabular}

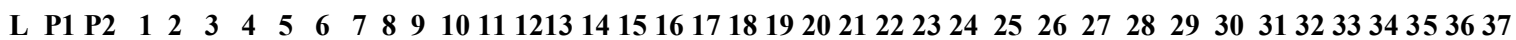

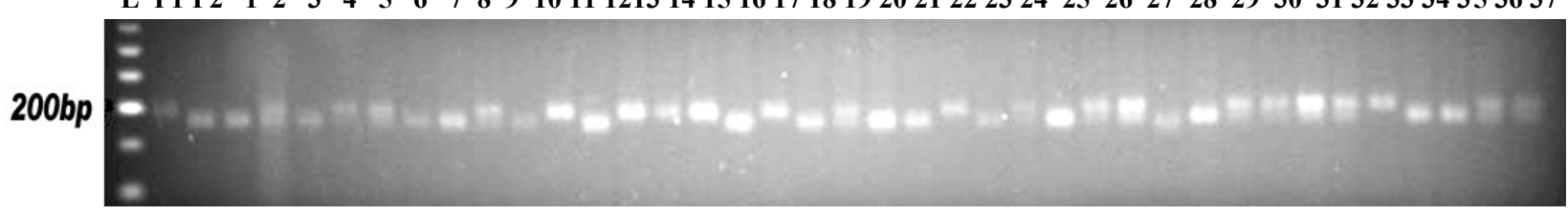

Fig. 1. Agarose gel showing polymorphic bands of $F_{2}$ plants from cross PBW373 $x$ WH1081 along with parental genotypes using SSRs Xgwm337. 


\section{$\begin{array}{llllllllllllllllllllllll}\text { P1 } & \text { P2 } & 1 & 2 & 3 & 4 & \text { L } & 5 & 6 & 7 & 8 & 9 & \text { L } & 10 & 11 & 12 & 13 & 15 & \text { L } & 16 & 17 & 18 & 19 & 20\end{array}$}

$130 \mathrm{bp}$

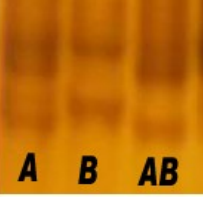

Fig. 2. Polyacrylamide gel showing polymorphic bands of $F_{2}$ plants from cross PBW373 $x$ WH1081 along with parental genotypes using SSRS Xbarc1044.
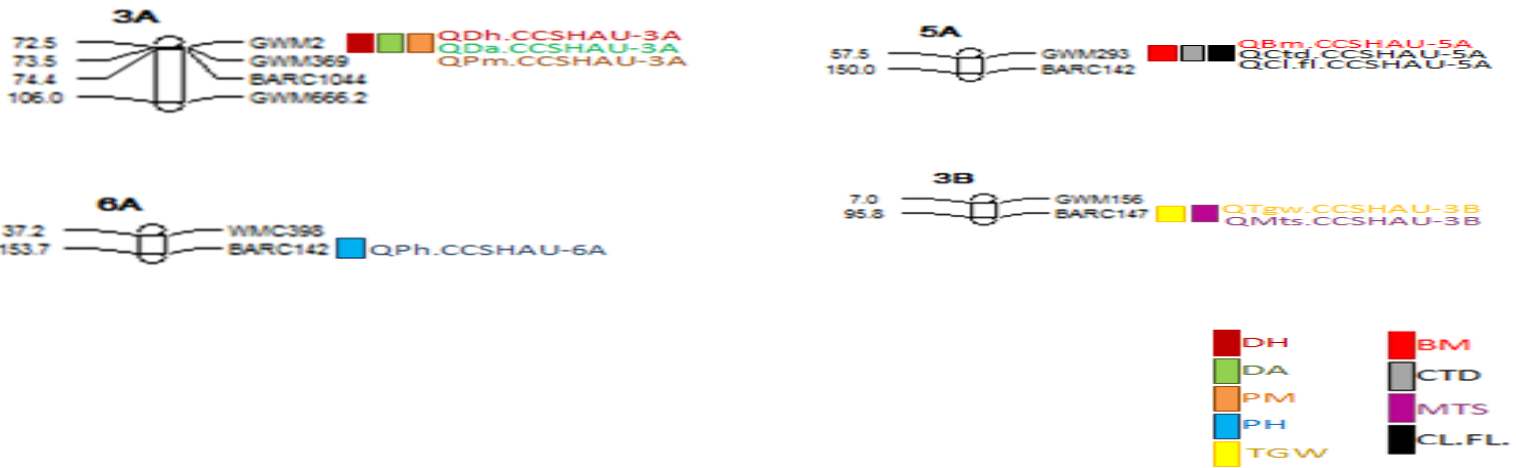

Fig 3. Maps showing the location of 9 QTLs on different chromosomes for physiological, yield related traits using cross PBW373 × WH1081.

ficient scope for further selection of the traits under consideration. $F_{2}$ population of 152 plants from viz; PBW373 (thermotolerant) $\times$ WH1081 (thermo sensitive) was phenotyped for heat stress related physiological, yield and its component traits. The population exhibited large variability for each trait.

Out of 200 SSRs used for amplification of parental DNA 158 SSRs (79\%) showed amplification in parents out of which 22 SSRs (13.9\% amplified SSRs) produced polymorphic bands. A total of 32 bands were observed. The number of alleles scored ranged from 1 to 3 with an average of 1.45 alleles (Table 1).

Association of QTLs with phenotypic traits (Single marker analysis, SMA): The single marker analysis allows the estimation of potential QTL by identifying markers segregating with phenotypic traits. This simple analysis was conducted with 22 SSRs to assess association of different traits with a marker using $\mathrm{F}_{2}$ population. Three markers were detected to have association with QTL for days to heading (significant at 5\% level). First two markers (Xbarc1044, Xgwm666.2) were mapped on $3 \mathrm{~A}$ while one Xgwm635 on 7A chromosome (Figs. 1 and 2). Two markers were detected to have association with QTL for days to anthesis (at 5\% level significance) and these markers (Xgwm635and $X g d m 125)$ were mapped on 7A and 4D chromosomes, respectively. One markers (Xwmc473) was detected to have significant association with QTL (at 5\% level) for days to physiological maturity, mapped on 4D chromosome. Total two markers were detected to have significant association with QTL for grain filling duration at 5\% level of significance. Xbarc142 and Xwmc473 markers were mapped on 5A and 4D chromosomes. In $F_{2}$ population, three markers were detected to have association with QTL for plant height at 5\% level significance. Xbarc142 and Xgwm337 markers were mapped on 5A while $X w m c 336$ marker was mapped on $1 \mathrm{D}$ chromosome respectively. Two markers were detected to have association with QTL for number of productive tillers/plant with significance at 5\% level. Xgwm2 and Xgwm666.2 markers were mapped on 3A chromosome. Only one marker (Xbarc142) was detected to have association for number of grains/spike with significance at 5\% level and mapped on $5 \mathrm{~A}$ chromosome. Two markers were detected to have association with QTL for 1000 grain weight at 5\% level of significance while other was found to be associated with QTL at $0.1 \%$ significant level. Xbarc142 and $X w m c 473$ markers were found to be mapped on $5 \mathrm{~A}$ and 4D chromosomes. One marker each Xgwm2 was detected to have significant association with QTL for grain yield/plant (at 5\% level) mapped on 3A chromosome, Xgwm156 for membrane thermostability mapped on 3B chromosome and Xgwm611 for chlorophyll fluorescence with significance at 5\% level and mapped on $7 \mathrm{~B}$ chromosome (Table 2). The result of regression analysis of each of the traits (i.e. plant height, number of productive tillers/plant, days to heading, days to anthesis, days to physiological maturity, grain filling duration, number of grains/spike, 1000 grain weight, grain yield/ plant, membrane thermostability and chlorophyll fluorescence) on individual markers was significant at $5 \%$ to $1 \%$ levels (Table 2). Yang et al. (2002) also detected two QTLs for heat tolerance measured by grain filling duration with the method of single factor analysis in an $\mathrm{F}_{2}$ population. Pandey et al. (2013) screened Raj 4014 and WH 730 with different SSR markers. Out of 300 SSR markers 
tested, 15\% were found polymorphic. These polymorphic markers were utilized for genotyping a subset of RILs that had clear contrasting variation for difference in grain filling rate. To check for potential cosegregation of DNA fragments and heat tolerant phenotypes, simple regression analysis was carried out in order to confirm an association between the markers and the grain filling rate as indicator for heat tolerance. Out of the 35 markers tested, relationship between the two markers Xbarc04 and Xgwm314 and the phenotypes of RILs got established which were highly significant.

\section{Composite interval mapping (CIM)}

Construction of linkage maps: The 22 SSRs were used to construct the map by using the mapmaker. These were mapped on 16 linkage groups. The number of markers on these 16 linkage groups varied from one to four. One marker (Xwmc336) was found to be present on linkage groups $1 \mathrm{~A}$ covering a length of 24.3 $\mathrm{cM}$ whereas linkage group $1 \mathrm{~B}$ and $1 \mathrm{D}$ covered a length of $25.0 \mathrm{cM}$ and $47.2 \mathrm{cM}$ with one (Xgwm413) and two (Xgwm337 and Xwmc336) markers respectively. Similarly 2A and 2D contained one (Xwmc170) and two (Xbarc142 and Xwmc170) markers with overall chromosome length of $131.2 \mathrm{cM}$ and $274.1 \mathrm{cM}$ respectively. Four markers (Xgwm2, Xgwm369, Xbarc1044 and $X g w m 666.2$ ) were found to be present on linkage group 3A, two markers (Xgwm156, Xbar147 and $X g d m 8, X c f d 70$ ) each were present on 3B and 3D covered a total length of $326.4 \mathrm{cM}, 102.8 \mathrm{cM}$ and 131.5 cM. Linkage groups 4A and 4D covered a length of $181.0 \mathrm{cM}$ and $386.2 \mathrm{cM}$ with one $(X w m c 313)$ and two (Xwmc473, Xgdm125) markers respectively. Two markers (Xgwm293, Xbarc142) were found to be present on linkage group 5A covered a length of 207.5 $\mathrm{cM}$. On the otherhand chromosome $6 \mathrm{~A}$ and $6 \mathrm{~B}$ covered a length of $190.9 \mathrm{cM}$ and $55.6 \mathrm{cM}$ with two (Xwmc398, Xbarc142) and one marker respectively. Two markers (Xgwm635, Xgwm260) on 7A and one marker (Xgwm611 and Xgwm635) each was found to be present on linkage group 7B and 7D with length of $296.0 \mathrm{cM}, 89.0 \mathrm{cM}$ and $80.5 \mathrm{cM}$. The total linkage coverage and average interval distance were 116.00 $\mathrm{cM}$ and $5.27 \mathrm{cM} /$ Marker, respectively. The A-, B- and D- genomes had $1360.3 \mathrm{cM}, 272.4 \mathrm{cM}$ and $919.5 \mathrm{cM}$ with average interval distance of $104.63 \mathrm{cM}, 54.48 \mathrm{cM}$ and $102.16 \mathrm{cM} /$ Marker. Partial genome maps were used in the present study and main effect QTL was detected by composite interval mapping using WinQTL Cartographer version-2.5. A logarithm of odds (LOD) score of 2.5 was used for suggesting the presence of a putative QTL.

Threshold LOD scores, calculated using 1000 permutations, were used for declaring definitive QTL. A total of nine QTLs were resolved following CIM (Table 3) of these, only one QTL was detected at a LOD score equal to threshold (2.5) value while eight were detected above the threshold value. The phenotypic variation explained by individual QTL ranged from $0.2 \%$ to $90.1 \%$.

All the nine QTLs were having definitive located on chromosome 3A (QDh.CCSHAU-3A, QDa.CCSHAU-3A and QPm.CCSHAU-3A), cromosome 5A (QBm.CCSHAU5A,QCtd.CCSHAU-5Aand QCl.fl.CCSHAU-5A), chromosome 6A (QPh.CCSHAU-6A) and chromosome 3B (QTgw.CCSHAU and QMts.CCSHAU-3B). Positive QTL effect suggested that an allele of the above QTL for heat stress tolerance is available in the tolerant parental genotype PBW373 (Fig. 3). Kumar et al. (2007) analyzed QTLs for grain weight ( $\mathrm{GW}=1000$ grain weight $)$ in common wheat using a set of 100 recombinant inbred lines (RILs) derived from a cross 'Rye Selection 111 (high GW) $\times$ Chinese Spring (low GW)'. Genotyping of RILs was done using 449 (30 SSRs, 299 AFLP and 120 SAMPL) polymorphic markers. QTL analysis for GW was conducted following genome-wide single marker regression analysis (SMA) and composite interval mapping (CIM) using molecular maps for the three chromosomes. Following SMA, 12 markers showed associations with GW, individual markers explaining $6.57 \%$ to $10.76 \% \mathrm{PV}$ (phenotypic variation) for $\mathrm{GW}$ in individual environments. The CIM identified two stable and definitive QTLs, one each on chromosome arms $2 \mathrm{BS}$ and 7AS, which were also identified through SMA and a third suggestive QTL on 1AS. These QTLs explained $9.06 \%$ to $19.85 \%$ PV for GW in different environments. Paliwal et al. (2012) prepared a linkage map comprising 160 simple sequence repeat markers covering the whole genome of wheat. Using composite interval mapping, significant genomic regions on $2 \mathrm{~B}, 7 \mathrm{~B}$ and $7 \mathrm{D}$ were found to be associated with heat tolerance. Of these, two (2B and 7B) were co-localized QTL and explained more than $15 \%$ phenotypic variation for HSITGW, HSIGFD and CTD. The three major QTL obtained can be used in marker-assisted selection for heat stress in wheat.

\section{Conclusion}

Molecular markers are useful for breeders in selecting quantitative trait loci (QTL), where a trait has polygenic inheritance with variable heritability and needs to be selected in variable environments over generations. The objective of this study was to map and characterize quantitative trait loci controlling heat tolerance measured by different heat stress related physiological, yield and yield related traits in late sown conditions and to find the molecular markers associated with them. So the present study concluded that heat stress caused due to delayed sowing leads to reduction in mean performance of the varieties for almost all economic traits. However this reduction can be avoided to some extent by using thermo tolerant varieties. Breeding for such genotypes/varieties can be eased by identifying markers using molecular marker assisted selection. 


\section{REFERENCES}

Badaruddin, M., Reynolds, M.P. and Ageeb, O.A.A. (1999). Wheat management in warm environments: effect of organic and inorganic fertilizers, irrigation frequency, and mulching. Agron J., 91: 975-983.

Basten, C.J., Weir, B.S. and Zeng, Z.B. (2000). QTL Cartographer, Version 1.15. A Reference Manual and Tutorial for QTL Mapping. Department of Statistics, North Carolina State University, Raleigh, NC.

Borner, A., Schumann, E., Furste, A., Coster, H., Leithold, B., Roder, S. and Weber, E. (2002). Mapping of quantitative trait loci determining agronomic important characters in hexaploid wheat (Triticum aestivum L.). Theor. Appl. Genet., 105(6-7): 921-936.

Chen, X., Temnykh, S., Xu, Y., Cho, Y.G. and McCouch, S.R. (1997). Development of a microsatellite framework map providing genome-wide coverage in rice (Oryza sativa L.). Theor. Appl. Genet., 95: 553-567.

Chu, C.G., Chao, S., Friesen, T.L., Faris, J.D., Zhong, S. and $\mathrm{Xu}$, S.S. (2010). Identification of novel tan spot resistance QTLs using an SSR-based linkage map of tetraploid wheat. Mol. Breed., 25: 327-338.

Dias, A.S and Lidon, F.C. (2009). Evaluation of grain filling rate and duration in bread and durum wheat, under heat stress after anthesis. J. Agron. Crop Sci., 195: 137-147.

Fischer, R.A. and Byerlee, D.B. (1991). Trends of wheat production in the warmer areas: Major issues and economic consideration. P.3-27. In: wheat for the nontraditional warm areas. Proc. Conf., Iguazu, Brazil. 29 July-3 Aug. 1990. CIMMYT. Mexico. DF.

IPCC (2012). Managing the Risks of Extreme Events and Disastersto Advance Climate Change Adaptation. A Special Report of Working Groups I and II of the Intergovernmental Panel on Climate Change, eds C. B. Field, V. Barros, T. F. Stocker, D. Qin, D. J. Dokken, K. L. M. D. Ebi, et al. (Cam- bridge: Cambridge University Press). 582p.

Kumar, N., Kulwal, P.L., Balyan, H.S. and Gupta, P.K. (2007). QTL mapping for yield and yield contributing traits in two mapping populations of bread wheat. Mol. Breed., 19: 163-177.

Kumar, R., Prasad, B.K., Singh, M.K., Verma, A. and Tyagi, B.S. (2014). Genetic analysis for phenological and physiological traits in wheat (Triticum aestivum L.) under heat stress environment. Indian J. Agric. Res., 43 (1): 62-66.

Paliwal, R., Roder, M.S., Kumar, U., Srivastava, J.P. and Joshi, A.K. (2012). QTL mapping of terminal heat tolerance in hexaploid wheat (Triticum aestivum L.). Theor. Appl. Genet., 125: 561-575.

Pandey, G.C., Jagadish, R.J., Sareen, S., Siwach, P., Singh, N.K. and Tiwari, R. (2013). Molecular investigations on grain filling rate under terminal heat stress in bread wheat (Triticum aestivum L.). African J. Biotech., 12 (28): 4439-4445.
Peleg, Z.Y., Saranga, T. Suprunova, Y., Ronin, M.S., Roder, A., Kilian, A.B., Korol and Fahima, T. (2008). Highdensity genetic map of durum wheat $x$ wild emmer wheat based on SSR and DArT markers. Theor. Appl. Genet., 117: 103-115.

Rane, J., Pannu, R.K., Sohu, V.S., Saini, R.S., Mishra, B., Shoran, J., Crossa, J., Vargas, M., Joshi, K. (2007). Performance of yield and stability of advanced wheat cultivar under heat stress environments of the indogangetic plains. Crop Sci., 47: 1561-1572.

Rustgi, S., Shafqat, M.N., Kumar, N., Baenziger, P.S., Ali, M.L., Dweikat, I.B., Campbell, T. and Gill, K.S. (2013). Genetic Dissection of Yield and Its Component Traits Using High-Density Composite Map of Wheat Chromosome 3A: Bridging Gaps between QTLs and Underlying Genes. PLOS. 8(7): 1-12.

Sadat, S., Saeid, K.A., Bihamta, M.R., Torabi, S., Salekdeh, S.G.H. and Ayeneh, G.A.L. (2013). Marker Assisted Selection for Heat Tolerance in Bread Wheat. World Appl. Sci. J., 21(8): 1181-1189.

Saghai-Maroof, M.A., Soliman, K.M., Jorgensen, R.A. and Allard, R.W. (1984). Ribosomal DNA spacer length polymorphism in barley: Mendelian inheritance, chromosomal location and population dynamics. Proc. Nat. Acad .Sci. (USA). 81: 8014-8018.

Talukdar, S.K., Babar, M.A., Vijayalakshmi, K., Poland, J., Prasad, P.V.V., Bowden, R. and Fritz, A. (2014). Mapping QTL for the traits associated with heat tolerance in wheat (Triticum aestivum L.). MBC Genetics, 1597: 113.

Tewolde, H., Fernandez, C.J. and Erickson, C.A. (2006). Wheat cultivars adapted to post-heading high temperature stress. J. Agron. Crop Sci., 192: 111-120.

Wang, R.X., Hai, L., Zhang, X.Y., You, G.X., Yan, C.S. and Xiao, S.H. (2009). QTL mapping for grain filling rate and yield-related traits in RILs of the Chinese winter wheat population Heshangmai 9 Yu8679. Theor. Appl. Genet., 118: 313-325.

Wang, S., Basten, C.J., Zeng, Z.B. (2010). Windows QTL cartographer 2.5. Department of Statistics, North Carolina State University, Raleigh, NC, (http:// statgen.ncsu.edu/qtlcart/WQTLCart.htm).

Wollenweber, B., Porter, J.R. and Schellberg, J. (2003). Lack of interaction between extreme high-temperature events at vegetative and reproductive growth stages in wheat. J. Agron. Crop Sci., 189: 142-150.

Wu, X.S., Wang, Z.H., Chang, X.P. and Jing, R.L. (2010). Genetic dissection of the developmental behaviours of plant height in wheat under diverse water regimes. $J$. Exp. Bot., 61: 2923-2937.

Yang, J., Sears, R.G., Gill, B.S. and Paulsen, G.M. (2002). Quantitative and molecular characterization of heat tolerance in hexaploid wheat. Euphytica, 126: 275-282.

Zeng, Z.B. (1994). Precision mapping of quantitative trait loci. Genetics, 136: 1457-1468. 